\title{
Un regard créateur sur l'Autre de l'art. Les Fauves et die Brücke (1905-1914) : primitivisme, colonialisme et art moderne
}

\section{Hélène Ivanoff}

\section{(2) OpenEdition \\ Journals}

Édition électronique

URL : http://journals.openedition.org/ifha/7414

DOI : $10.4000 /$ ifha. 7414

ISSN : 2198-8943

\section{Éditeur}

IFRA - Institut franco-allemand (sciences historiques et sociales)

\section{Édition imprimée}

Date de publication : 1 décembre 2013

ISSN : 2190-0078

\section{Référence électronique}

Hélène Ivanoff, « Un regard créateur sur l'Autre de l'art. Les Fauves et die Brücke (1905-1914):

primitivisme, colonialisme et art moderne », Revue de l'IFHA [En ligne], 5 | 2013, mis en ligne le 17

février 2014, consulté le 20 avril 2019. URL : http://journals.openedition.org/ifha/7414 ; DOI : 10.4000/ ifha.7414

Ce document a été généré automatiquement le 20 avril 2019.

(CIFHA 


\title{
Un regard créateur sur l'Autre de l'art. Les Fauves et die Brücke (1905-1914): primitivisme, colonialisme et art moderne
}

\author{
Hélène Ivanoff
}

\section{NOTE DE L'ÉDITEUR}

Thèse de doctorat sous la direction de Michael Werner, EHESS, soutenue le 9 mai 2012 à Paris.

1 S'inscrivant dans les problématiques de l'histoire croisée et des études postcoloniales, cette thèse d'histoire culturelle étudie les transferts artistiques, et plus largement culturels, au prisme de la création des Fauves et de die Brücke entre 1905 et 1914. Elle montre l'articulation entre transferts artistiques, expansion coloniale, développement du savoir ethnologique, et crise de la culture européenne en France et en Allemagne. Ces conditions historiques ont favorisé l'émergence d'une nouvelle catégorie esthétique sur la scène artistique, le primitivisme ; elle permit aux artistes d'Europe de mettre en crise les règles de l'art du vieux continent. Cette thèse se penche donc sur les relations entre primitivisme, colonialisme et art moderne, à une période charnière de l'histoire de l'art, à un tournant : l'entrée des avant-gardes dans la modernité.

2 Pourquoi parler d'une histoire culturelle du primitivisme? Sans doute parce qu'il était nécessaire de se distinguer d'une histoire de l'art qui se consacrait uniquement à l'histoire des œuvres d'art en Europe, sans prendre en considération le contexte culturel global de leur création et les phénomènes d'appropriations culturelles à l'œuvre dans les processus créatifs. L'objectif était aussi de se replacer dans une approche de l'histoire de l'art qui interrogeait la signification de l'œuvre à partir de sa forme, cherchant à mettre 
en lumière les identités, les représentations et les idéologies collectives de son temps, que manifestent et engendrent la création artistique. En se plaçant au-delà des cultures, il s'agissait d'analyser les processus d'acculturation et de réappropriations culturelles, particulièrement nombreux en cette période de forte expansion coloniale.

Si la globalisation actuelle a mis le focus sur ces phénomènes de métissage et d'hybridité culturelle, il est bien évident que l'histoire des transferts culturels s'est penchée - depuis longtemps et peut-être en des termes plus appropriés - sur les phénomènes de resémantisation culturelle, notamment entre la France et l'Allemagne du $\mathrm{XIX}^{\mathrm{e}}$ et $\mathrm{XX}^{\mathrm{e}}$ siècles, depuis les études de Michael Werner et de Michel Espagne dans les années 1980. Cette approche transnationale a été étendue dans cette étude d'histoire culturelle à d'autres champs géographiques sous domination coloniale afin de mieux comprendre ce qui fondait la spécificité de la culture européenne autour de 1900 et de saisir ce qu'étaient les « arts primitifs » pour les artistes d'Europe.

4 Or le primitivisme, ou plus précisément, selon l'expression utilisée par Daniel Fabre, la façon dont les artistes tinrent un discours sur un "Autre de l'art» en Europe, et portèrent un regard créateur sur ses œuvres, semblent bien être un précieux révélateur des échanges culturels au début $\mathrm{du} \mathrm{XX}^{\mathrm{e}}$ siècle et des modes d'appropriation culturelle durant la période coloniale. Quel fut ainsi le rôle des artistes d'avant-garde dans ces processus de circulation, de traduction et de réinterprétation culturelle? Quels phénomènes d'interactions entre différents champs culturels révèlent leurs créations et leur discours esthétiques? S'ils furent les témoins des représentations dominantes de leurs contemporains, quelles nouvelles visions esthétiques et culturelles diffusèrent-ils en Europe?

5 Autant de questions auxquelles cette thèse tente de répondre à partir du cas de deux groupes d'artistes contemporains, les Fauves - principalement Matisse, Derain, Vlaminck - et die Brücke - notamment Kirchner, Heckel, Pechstein, Schmidt-Rottluff et Nolde - car au sein de l'avant-garde européenne, ce sont eux qui attirèrent l'attention de façon pionnière sur un "Autre de l'art" en France et en Allemagne: ils participèrent à l'invention des "arts primitifs", firent entrer des productions matérielles dans le domaine de l'art dont elles étaient en grande partie exclues en Europe et propagèrent le terme de primitivisme sur la scène artistique européenne. Au lieu d'essentialiser cette catégorie esthétique, la thèse s'emploie à la déconstruire et à montrer comment les artistes contribuèrent également ainsi à la construction d'un discours sur l'Autre.

6 Bien qu'étant avant tout une thèse d'histoire culturelle, la méthode adoptée se réfère aussi à la tradition iconologique telle qu'elle fut présentée et défendue par Erwin Panofsky, Aby Warburg et Ernst Cassirer. Dans le souci du détail enseigné par Daniel Arasse, il s'agit de porter attention aux motifs, à ce qui fait « symptôme » dans les œuvres d'art et discours esthétiques, effraction dans le modèle classique de représentation occidentale et rupture dans un "régime de normalité » dirait Georges Didi-Hubermann. Afin de repérer les traces d'échanges culturels dans la création artistique européenne et de montrer comment les artistes ont inséré dans leurs œuvres des conceptions et des formes esthétiques étrangères à l'histoire de l'art européen, elle confronte les productions artistiques de l'avant-garde aux cultures visuelles contemporaines et montrent comment les artistes occidentaux s'approprièrent les collections ethnographiques, préhistoriques et découvertes archéologiques dans leurs processus créatifs. En outre, elle interroge aussi les sources textuelles de l'époque pour mieux saisir 
les primitivismes du début du $\mathrm{XX}^{\mathrm{e}}$ siècle et cerner les perceptions et les représentations européennes dominantes à l'époque.

Dans la première partie, sous le titre "L'évolution d'un regard ", se trouve analysé le rôle joué par les artistes pour engager un processus «d'artialisation » ou «d'artification » de l'objet ethnographique ou « oriental », tel qu'on pouvait l'observer au début du XXe siècle dans les musées, les collections privées, les spectacles exotiques et coloniaux, ou lors de voyages dans les Empires coloniaux. Les Fauves et die Brücke furent parmi les premiers artistes en France et en Allemagne à reconnaître les qualités esthétiques des objets venant d'Asie, d'Afrique, d'Océanie et d'Amérique et à interroger dans leurs processus créateurs des objets et des conceptions esthétiques provenant de cultures qualifiées à l'époque de "primitives" par opposition à la culture européenne. Ils prirent pour modèles des indigènes que l'on exhibait comme spécimen d'une race ou que l'on présentait pour leur anormalité, notamment lors des expositions coloniales. En cela, ils témoignaient des sensibilités de leur temps, l' «art nègre ", l' « Orient ", « l'art primitif » correspondant à des catégories "fantasmagoriques" pour évoquer des esthétiques contestant les modèles artistiques dominants en Europe. Cependant, si le discours de l'avant-garde artistique est indissociable des logiques d'appropriation coloniale et correspond, selon Emmanuelle Sibeud, à la « face lumineuse d'un discours plus global sur les sociétés colonisées ", ils contribuèrent en même temps à modifier les représentations collectives européennes: par leurs créations et leurs discours, ils procédaient à une "décolonisation par l'art» en mettant sur un pied d'égalité culture européenne et cultures dites « primitives».

Dans les trois parties suivantes, la thèse présente les acteurs responsables de transferts artistiques entre les artistes d'Europe et ceux des aires amérindiennes, océaniennes et africaines. «Les trajectoires des regards » portés par les artistes sur les aires culturelles non-européennes ont été suivies, non pas en s'appuyant sur de simples affinités formelles, mais sur leurs esquisses, leurs correspondances et leurs livres: le parcours de certains artefacts de leur espace de production originelle jusqu'à leur représentation dans les œuvres des artistes occidentaux a ainsi pu être retracé, et les noms de certains artistes africains ou amérindiens identifiés, à l'instar d'Ateu Atsa ou de Charles Edenshaw. À l'origine des collectes ethnographiques se trouvent des colons, des ethnographes, des directeurs de cirques et de zoos, faisant parvenir en Europe d'importantes collections ou engageant des figurants pour les spectacles exotiques. Certains furent des «passeurs de culture " en rassemblant les littératures orales, en enregistrant les musiques traditionnelles et en observant les rites de religions dites primitives. Ces pionniers de l'ethnographie ont aussi rédigé de premiers écrits sur « l'art primitif », à l'instar de Franz Boas, Aby Warburg, Leo Frobenius, Emil Stephan ou Augustin Krämer. Ces artefacts, médiateurs de culture, ont changé de significations en traversant les frontières et la thèse met en évidence les identités et représentations culturelles successives qu'ils cristallisèrent.

9 La dernière partie, "la révolution du regard", montre que les artistes d'Europe s'approprièrent de façon matérielle, intellectuelle et visuelle ces nouvelles esthétiques non européennes. Ils se constituèrent des "palettes d'objets", des «bibliothèques de formes » et revinrent aux matières et techniques artisanales. Ils développèrent une nouvelle sensibilité artistique, qu'ils qualifièrent eux-mêmes de primitive. Ces œuvres d'art non européennes furent associées à d'autres productions européennes, prenant elles aussi un nouveau statut artistique: l'art des fous, des enfants, des hommes 
préhistoriques. En voie d'institutionnalisation, les sciences du début du XX $\mathrm{XX}^{\mathrm{e}}$ siècle - la psychologie, la psychiatrie, l'anthropologie, la préhistoire - ressentirent la nécessité de s'inventer un art, qui fut qualifié de primitif. L'invention des « arts primitifs » au début du $\mathrm{XX}^{\mathrm{e}}$ résultait de cette osmose des regards : regards des artistes, des archéologues, des historiens, des ethnologues et bientôt des marchands d'art. Or, ces "nouvelles" esthétiques venaient contester les modèles et les règles de représentation occidentale, elles furent un appui pour théoriser l'art moderne par opposition à l'art classique et académique, hérité en grande partie de la Renaissance et de l'idéal de beauté grecque fondé sur la mimésis. Reposant sur l'intuition et l'émotion, les "arts primitifs » incarnaient, d'après les artistes modernes, sensations et sentiments, étaient le symbole d'une création instinctive, spontanée et immédiate, conduite par un élan vital, par opposition à un mode de création raisonnée reposant sur la connaissance des styles. Alors que du côté des Fauves, l'appropriation était essentiellement esthétique, il semble bien que les artistes de die Brücke, imprégnés des idées de la Kultukritik et engagés dans les mouvements de la Lebensreform, aient trouvé dans ces «mondes primitifs » de nouveaux modèles culturels, aptes à contester le modèle de civilisation occidentale.

En somme, la création artistique des Fauves et de die Brücke est le reflet de visions esthétiques et culturelles dominantes en Europe. Leurs œuvres donnent accès aux représentations européennes du début du XXe siècle, et rappelle que le primitivisme naît simultanément à l'émergence de l'ethnologie et de l'ethnographie comme savoir disciplinaire dans une France et une Allemagne coloniales, au moment précis où cette culture savante devient une culture populaire par l'intermédiaire des premiers loisirs de masse. Le primitivisme de die Brücke se distingue toutefois nettement de celui des Fauves, par ses aspects théâtraux dans leur mode et cadres de vie: architectes de formation, ils élaborèrent pour leurs ateliers de véritables œuvres d'art total, empreintes de primitivismes. Le primitivisme de die Brücke est aussi plus mimétique et formel que le primitivisme analytique des Fauves. Incontestablement, il prenait les aspects d'une contestation culturelle en Allemagne, moins présente en France. La richesse et la variété des arts dits primitifs sur la scène artistique allemande s'explique, quant à elle, par l'importance des collections et des recherches ethnographiques menées Outre-Rhin, plus que par les expansions coloniales respectives.

$11 \mathrm{Au}$ même titre que l'orientalisme fut "un style occidental de domination, de restructuration et d'autorité sur l'Orient» selon les propos d'Eduard Saïd, les arts primitifs sont bien ici une construction culturelle de l'Occident, inscrite dans le temps colonial, les primitivismes prenant des aspects variés et différenciés selon les contextes nationaux où il émerge et les stratégies des acteurs à l'origine de ce discours. Il est un regard que des artistes ont posé sur un "Autre de l'art ", et ce regard est informé par leur propre culture; les perceptions et les sensibilités étant inscrites dans l'histoire, les créations artistiques gardent la trace des images et des représentations qui ont imprégné l'œil et l'esprit des artistes. Cependant, il est bien évident que la création artistique contribue, elle aussi, à modifier les perceptions et représentations collectives. Dans l'histoire du goût occidental, les artistes modernes ont modifié l'image des sociétés sous emprise coloniale et ont ouvert la voie à une reconnaissance de leurs arts sur la scène artistique européenne. Parce qu'ils sont eux-mêmes créateurs de formes, les artistes sont à la fois des témoins, mais aussi des acteurs de la construction du regard d'une société, soit de ses visions esthétiques et culturelles. 